\title{
Indução do estro em cutias (Dasyprocta leporina) utilizando-se protocolos à base de prostaglandina isolada ou em associação com análogo de GnRH
}

\author{
[Estrus induction in agoutis (Dasyprocta leporina) using protocols based on prostaglandin isolated \\ or in association to GnRH analogue] \\ G.C.X. Peixoto ${ }^{1}$, K.M. Maia ${ }^{1}$, L.M. Almeida ${ }^{1}$, L.B. Campos ${ }^{1}$, G.B. Oliveira ${ }^{1}$, \\ M.F. Oliveira ${ }^{1}$, A.B. Brito ${ }^{2}$, S.F.S. Domingues ${ }^{2}$, A.R. Silva ${ }^{1} *$ \\ ${ }^{1}$ Universidade Federal Rural do Semiárido - Mossoró, RN \\ ${ }^{2}$ Universidade Federal do Pará - Castanhal, PA
}

\begin{abstract}
RESUMO
Comparou-se a eficiência de protocolos para indução de estro em cutias. Em cinco fêmeas, foram administradas duas doses de cloprostenol $(5 \mu \mathrm{g}) \mathrm{com}$ intervalo de nove dias, via intraperitoneal; em outras cinco, administraram-se $30 \mu \mathrm{g}$ de análogo do hormônio liberador de gonadotrofinas $(\mathrm{GnRH})$, via intravulvar, seguidos de $5 \mu \mathrm{g}$ de cloprostenol, via intraperitoneal, após sete dias e, após mais dois dias, nova dose do análogo de GnRH. A cada três dias, a ciclicidade reprodutiva dos animais foi monitorada, por meio de coleta de sangue, para dosagem hormonal, ultrassonografia ovariana e citologia vaginal. Duas das fêmeas que receberam apenas prostaglandina, as quais estavam em fase luteal no início do tratamento, manifestaram o estro aos três e seis dias após a segunda administração da droga. Já nas fêmeas que receberam a prostaglandina associada ao análogo do $\mathrm{GnRH}$, duas que originalmente estavam em fase luteal apresentaram estro aos quatro dias após o tratamento, e uma outra apenas após 10 dias. Não foram evidenciadas diferenças estatísticas quanto à eficiência dos tratamentos $(\mathrm{P}>0,05)$. Conclui-se que, de acordo com os protocolos utilizados, o uso da prostaglandina isolada ou em associação com análogo do GnRH para a indução do estro em cutias $D$. leporina apresenta eficiência limitada às fêmeas que estejam em fase luteal por ocasião do início do tratamento.
\end{abstract}

Palavras-chave: cutias, estro, prostaglandina, GnRH

\begin{abstract}
We compared the efficiency of protocols for estrus induction in agoutis. Five females received double intraperitoneal administration of cloprostenol $(5 \mu \mathrm{g})$ on a 2-days interval; other five females were treated with intravulvar administration of $30 \mu \mathrm{g}$ gonadotrophin release hormone analogue (GnRH associated to intraperitoneal administration of $5 \mu \mathrm{g}$ cloprostenol after seven days and a new administration of GnRH analogue after two days. Every 3 days, the agoutis' reproductive cycle was monitored by blood collection for hormonal analysis, ovarian ultrasound and vaginal cytology. Two females, originally in luteal phase, that received isolated prostaglandin presented estrous signs at 3 and 6 days after the second drug administration. From the females that received the association, two that were originally in luteal phase presented estrus at 4 days after treatment, and one other presented estrus only after 10 days. There was no significant statistical difference regarding the efficiency of treatments for estrus induction $(P>0.05)$. We conclude that, according to the protocols tested in the study, the use of isolated prostaglandin or its association to GnRH analogue for estrus induction in D. leporine shows an efficiency limited to the females that were in luteal phase in the beginning of the treatment.
\end{abstract}

Keywords: agoutis, estrus, prostaglandin, GnRH

Recebido em 30 de março de 2017

Aceito em 19 de junho de 2017

* Autor para correspondência (corresponding author)

E-mail: legio2000@yahoo.com 


\section{INTRODUÇÃO}

O termo cutia designa muitas espécies de roedores do gênero Dasyprocta, que são nativos das Américas Central e do Sul (Kaiser et al., 2011). Entre essas espécies, a Dasyprocta leporina, que possui população classificada como estável (Red..., 2015), vive em distintos habitats, incluindo o semiárido brasileiro (Carvalho et al., 2008). A referida espécie tem sido considerada como fonte alimentar de proteína para nativos, além de ser importante dispersor de sementes para manutenção do equilíbrio ecológico (Silva et al., 2012). Adicionalmente, a aceitação de sua carne e couro pelo mercado internacional tem encorajado a reprodução de cutias em cativeiro (Lopes et al., 2004). Nesse contexto, sua manutenção em cativeiro é dependente do conhecimento de seus parâmetros biológicos e reprodutivos, o que permite sua multiplicação e, consequentemente, sua conservação. No entanto, falhas na expressão de estro e redução da fertilidade em roedores têm sido descritas quando estes são submetidos a situações distintas, em especial ao estresse decorrente do cativeiro (Rensis e Scaramuzzi, 2003).

Esforços consideráveis têm aperfeiçoado o conhecimento sobre a reprodução em fêmeas de cutias (Guimarães et al., 2011), cujos estudos iniciais eram voltados para a descrição morfológica dos ovários (Almeida et al., 2003, das tubas uterinas (Fortes et al., 2005) e da placenta (Rodrigues et al., 2003) em D. leporina. Recentemente, o ciclo estral dessa espécie mantida em cativeiro no semiárido nordestino foi monitorado por citologia vaginal e ultrassonografia ovariana e foi descrito com duração média de 28,2 \pm 0,7 dias (Campos et al., 2015). No tocante ao desenvolvimento de técnicas de reprodução assistida para fêmeas de D. leporina, até então, estas limitam-se à criopreservação dos folículos ovarianos préantrais (Wanderley et al., 2012).

A manipulação da função ovariana, pela indução e pelo controle do momento da ovulação, proporciona o aumento da prolificidade natural, antecipando a puberdade e reduzindo o número de serviços por concepção, sem que seja necessária a detecção de estro (Pfeifer et al., 2014). Essa técnica pode ser implementada independentemente da época, permitindo uniformizar a produção animal e sincronizar o estro para acasalamento natural ou inseminação artificial, o que pode melhorar o desempenho reprodutivo de animais em cativeiro (Wei et al., 2015). Apesar dos vários tratamentos descritos para mamíferos domésticos, a aplicação do controle ovariano em roedores é ainda pouco estudada. Em ratos (Mus musculus), a administração intraperitoneal do cloprostenol, uma prostaglandina sintética, foi eficiente na indução de estro entre 72 e 96 horas após o término do tratamento (Pallares e GozalezBulnes, 2009). Porém, a mesma prostaglandina não conseguiu induzir o estro em porquinhos-daíndia (Cavia porcellus) (Grégoire et al., 2012), o que ressalta a variedade na resposta ovariana de acordo com a espécie. Por outro lado, o tratamento com agonista de GnRH isolado ou em associação com eCG foi útil não apenas para a indução, mas também para sincronização de estro e hiperestimulação ovariana em ratos (Rattus norvegicus) (Agca et al., 2013).

Em cutias, não há informações comparativas em relação aos efeitos da utilização de hormônios exógenos para a indução do estro. Ressalta-se que o desenvolvimento de tais protocolos possibilitaria uma adequação de técnicas de manejo reprodutivo para a espécie, inclusive, abrindo caminho para o uso da inseminação artificial. Desse modo, objetivou-se comparar a eficiência de dois protocolos, baseados no uso isolado de cloprostenol ou em associação com análogo de GnRH, para indução de estro em cutias $D$. leporina mantidas em cativeiro na região semiárida brasileira.

\section{MATERIAL E MÉTODOS}

A pesquisa foi autorizada pelo Comitê de Ética no Uso de Animais (Ceua) da Ufersa, Mossoró, Brasil (Processo no 23091.005467/2013-01). Os animais foram oriundos do Centro de Multiplicação de Animais Silvestres da Ufersa (Mossoró, RN, Brasil; 5¹0'S, 37¹0'W), localizado no semiárido nordestino, cuja temperatura média anual é de $27^{\circ} \mathrm{C}$. O experimento foi conduzido durante a estação seca, sob fotoperíodo natural de $12 \mathrm{~h}$. Foram utilizadas 10 fêmeas de cutias da espécie $D$. leporina, com idade média ( \pm DP) de $30 \pm 0,5$ meses e peso médio de $2,5 \pm 0,5 \mathrm{~kg}$, sexualmente maduras. Essas fêmeas foram mantidas isoladas dos machos a partir de quatro meses antes do 
início do estudo. Elas foram agrupadas e mantidas em recinto coberto $(4 \times 5 \mathrm{~m})$. Os indivíduos recebiam alimentação à base de ração comercial para roedores, constituída de $13 \%$ de proteína bruta, $16 \%$ de fibra e $1 \%$ de minerais. A água era fornecida ad libitum.

A anestesia foi realizada com o intuito de facilitar os procedimentos envolvidos na manipulação dos animais, tais como administração de drogas, realização da ultrassonografia e coleta sanguínea. A cada três dias, os animais foram submetidos a jejum de 12 horas, em seguida contidos fisicamente e anestesiados utilizando-se associação de cetamina $(15 \mathrm{mg} / \mathrm{kg} / \mathrm{IM}$; Ketalar, Pfizer, Brasil) e xilazina $\left(1 \mathrm{mg} / \mathrm{kg} / \mathrm{IM}\right.$; Sedomin ${ }^{\circledR}$, Konig SA, Brasil) (Campos et al., 2015). Durante todos os procedimentos, os animais foram monitorados quanto às variáveis fisiológicas, incluindo temperatura corporal, frequência cardíaca e respiratória.

As cutias foram separadas em dois grupos experimentais, cada um contendo cinco indivíduos. O primeiro grupo recebeu duas administrações intraperitoniais de $5 \mu \mathrm{g}$ de cloprostenol (Ciosin $\AA$, Schering-PloughCoopers, Brasil) em intervalo de nove dias (Weir et al., 2015). Já o segundo grupo recebeu uma injeção intravulvar de $30 \mu \mathrm{g}$ de análogo de hormônio liberador de gonadotrofina $(\mathrm{GnRH})$ (Sincrorrelin ${ }^{\circledR}$, Ouro Fino Saúde Animal Ltda., Brasil) associada a uma administração intraperitoneal de cloprostenol $(5 \mu \mathrm{g})$, bem como nova dose intravulvar de análogo do GnRH $(30 \mu \mathrm{g})$ após dois dias (Pfeifer et al., 2014, adaptado) (Fig. 1).

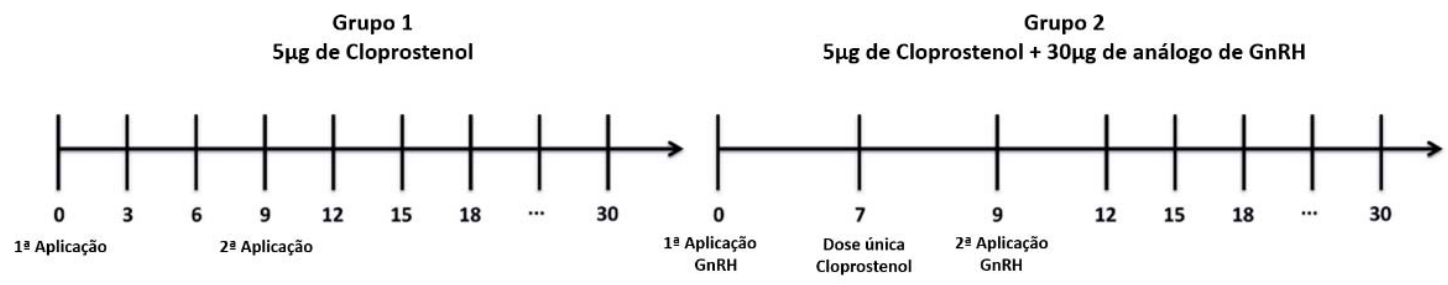

Figura 1. Delineamento experimental relativo ao uso de drogas para indução de estro em cutias Dasyprocta leporina.

O efeito dos fármacos nas fêmeas foi monitorado a cada três dias, por ultrassonografia ovariana e dosagem sanguínea para estrógeno e progesterona, e diariamente por citologia vaginal. As avaliações do ciclo estral iniciaramse três dias antes da primeira administração das drogas e perduraram por 30 dias. Em cada ocasião, as alterações da genitália externa foram também observadas.

As modificações de aparência vulvar durante as diferentes fases do ciclo estral foram monitoradas com base na metodologia previamente reportada por Campos et al. (2015). O exame da aparência vulvar incluía a observação e subsequente descrição dos lábios e comissuras da vulva, bem como a presença de muco no vestíbulo vaginal. A edemaciação e a hiperemia vulvar, assim como as características dos fluidos vaginais, mucoso ou sanguinolento, também foram descritas. Adicionalmente, a abertura vaginal externa era classificada como aberta ou fechada, identificada pela facilidade ou dificuldade da introdução do swab, respectivamente.

Para a citologia vaginal, realizou-se a fricção de swab contra a parede da região mais caudal da vagina, sendo as células transferidas para uma lâmina de vidro por rolamento, as quais eram coradas em panótico rápido (Instant-Prov ${ }^{\circledR}$, Newprov, Brasil). Por uso de microscopia de luz (400x), foram contadas 100 células e calculadas as proporções de células parabasais, intermediárias e superficiais nucleadas e anucleadas. A aparência e a proporção dos tipos celulares foram usadas para determinar a fase do ciclo estral das fêmeas, assim como descrito por Campos et al. (2015). 
Os ovários foram avaliados por ultrassonografia transabdominal, utilizando-se um aparelho portátil (AquilaVet; Pie Medical, Nutricell, Brasil), dotado de transdutor microconvexo nas frequências $6-8 \mathrm{MHz}$, em modo $\mathrm{B}$ e em tempo real. Os animais foram posicionados em decúbito dorsal, e o gel acústico foi aplicado na área a ser examinada. Os rins foram inicialmente identificados para facilitar a localização topográfica dos ovários, que foram mensurados e avaliados quanto à ecotextura e à ecogenicidade, bem como quanto à identificação e à mensuração das estruturas, como presença de folículos e corpos lúteos (Campos et al., 2015).

A dosagem das concentrações séricas do estradiol e da progesterona foi obtida por amostras de sangue de cada procedimento conduzido. A coleta de sangue foi realizada com auxílio de seringa de $1 \mathrm{~mL}$, nas veias cefálicas ou safenas. Em seguida, o sangue foi armazenado em tubos de vidro estéreis, que foram posteriormente submetidos à centrifugação (2000G/15min). Após esse procedimento, o soro foi separado e mantido em freezer $\left(-18^{\circ} \mathrm{C}\right)$. As dosagens de estradiol e progesterona foram determinadas por eletroquimioluminescência amplificada (Immunodiagnostic VITROS ${ }^{\circledR}$ ECiQ; Johnson \& Johnson do Brasil Indústria e Comércio de Produtos para Saúde Ltda., Brasil). Para tanto, os tubos com soro foram removidos do freezer, e, quando atingida a temperatura de 23 a $25^{\circ} \mathrm{C}$, as amostras foram homogeneizadas com auxílio de pipeta de $1 \mathrm{~mL}$. Os tubos foram colocados na bandeja própria do aparelho e, subsequentemente, no dispositivo apropriado. Após a seleção e o registro dos ensaios desejados, as mensurações hormonais foram realizadas automaticamente (Bartoskova et al., 2014). Os resultados obtidos foram apresentados em $\mathrm{pmol} / \mathrm{L}$ para estrógeno e nmol/L para progesterona, que foram, em seguida, transformados em $\mathrm{pg} / \mathrm{mL}$ e $\mathrm{ng} / \mathrm{mL}$, respectivamente. As fases estrogênica e progesterônica foram identificadas de acordo com os perfis para estrógeno no sangue anteriormente estabelecidos para cutias (Guimarães et al., 2011).

Os dados foram expressos em média e erropadrão e analisados pelo programa StatView (SAS Institute Inc., Cary, EUA). A eficiência dos protocolos para indução de estro foi avaliada pelo teste exato de Fisher $(\mathrm{P}<0,05)$. A comparação entre os protocolos no tocante aos valores hormonais e à citologia vaginal foi avaliada pelo teste PLSD de Fisher $(\mathrm{P}<0,05)$. As relações entre os níveis estrogênicos e as células vaginais foram determinadas por uma regressão linear simples $(\mathrm{P}<0,05)$.

\section{RESULTADOS}

No início do experimento, no grupo que recebeu somente prostaglandina, três animais estavam na fase luteal, e dois na fase folicular. No grupo tratado com a associação da prostaglandina e do análogo de GnRH, duas fêmeas estavam na fase luteal, e três fêmeas na fase folicular.

No tocante ao tratamento à base de prostaglandina isolada, apenas duas fêmeas $(40 \%)$ apresentaram características externas relacionadas com a manifestação de estro, como vulva aberta, edemaciada e hiperêmica, além de presença de muco vaginal (Fig. 2) e fácil penetração do swab, aos três e seis dias após a segunda administração da droga. Salienta-se que essas duas fêmeas que responderam à indução do estro estavam em fase luteal no início do tratamento.

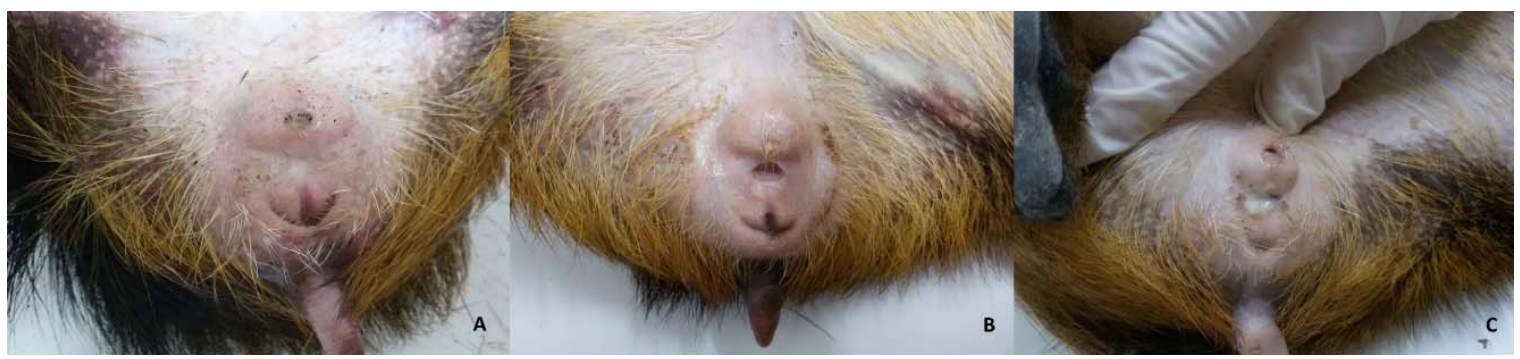

Figura 2. Características externas relacionadas com a manifestação de estro em cutias. 
Nessa ocasião, as fêmeas apresentaram elevações nos níveis de estrógeno de $22,4 \mathrm{pg} / \mathrm{mL}$ e $17,5 \mathrm{pg} / \mathrm{mL}$, com valores médios de progesterona baixos, 3,5 $\pm 0,2 \mathrm{ng} / \mathrm{mL}$. Para essas fêmeas, por uso da citologia vaginal, foi observada predominância de células superficiais $(63 \%$ e $82 \%$, respectivamente) com significativa influência estrogênica ( $\mathrm{R}=0,57 ; \mathrm{P}=0,0049)$. Em adição, por exame ultrassonográfico, foi identificado somente um folículo (20\%) em uma das fêmeas, descrito como uma estrutura circular e regular, contendo fluido hipoecogênico, localizada no centro do ovário, medindo $0,23 \mathrm{~cm}$ (Fig. 3).

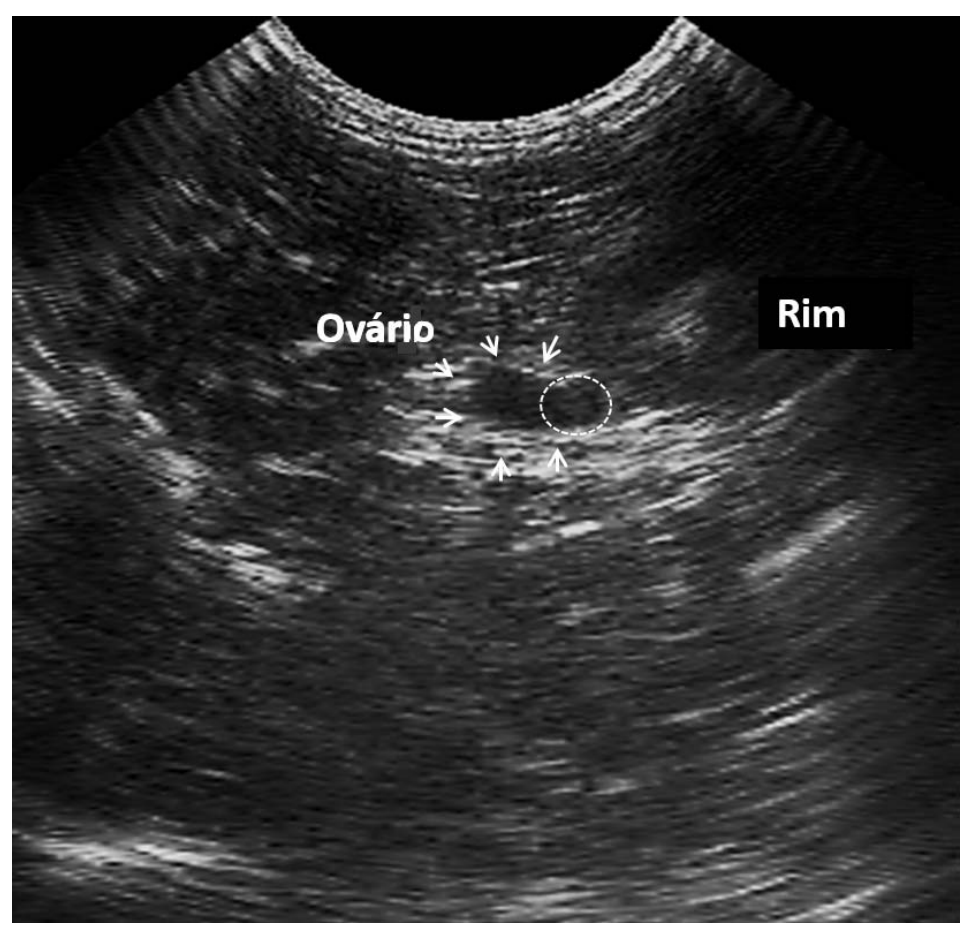

Figura 3. Identificação do folículo ovariano de cutias por meio do exame ultrassonográfico. Setas brancas indicam o ovário, e o círculo identifica a presença do folículo.

Entre as fêmeas que foram submetidas à associação de prostaglandina e análogo de GnRH, três $(60 \%)$ mostraram características externas de estro, principalmente abertura vulvar e muco vaginal em acentuado volume. Dessas fêmeas, duas $(40 \%)$, as quais estavam em fase luteal no início do procedimento, apresentaram elevações nos níveis de estrógeno (12,3 e $8,5 \mathrm{pg} / \mathrm{mL}$ ) aos quatro dias após o término do tratamento, com valores para progesterona de 2,5 e $2,3 \mathrm{ng} / \mathrm{mL}$, respectivamente. Adicionalmente, verificou-se predominância de $92 \%$ e $83 \%$ de células superficiais, com significativa influência estrogênica $\quad(\mathrm{R}=0,69 ; \quad \mathrm{P}=0,0003) ; \quad$ entretanto, nenhuma estrutura folicular ovariana foi identificada por meio da ultrassonografia. A outra fêmea (20\%), a qual estava em fase folicular no início do procedimento, apresentou resposta tardia, com pico de estrógeno $(8,3 \mathrm{pg} / \mathrm{mL})$ após 10 dias da última administração da droga. Neste dia, foi observada predominância de células superficiais $(73 \%)$ e identificação ultrassonográfica de folículo ovariano, medindo $0,13 \mathrm{~cm}$, localizado na periferia do órgão (Fig. 3).

Ao se compararem os tratamentos, verificou-se que ambos promoveram eficiência similar na indução de estro $(\mathrm{P}>0,05)$ nas cutias, ou seja, $40 \% \quad(2 / 5)$ nas fêmeas tratadas com prostaglandina isolada e $60 \%$ (3/5) nas fêmeas submetidas à associação de drogas. Vale salientar que, apesar da eficiência moderada na indução do estro, a sincronização desse evento não foi efetiva, haja vista que a manifestação estral ocorreu em dias diversos, conforme variação individual. 


\section{DISCUSSÃO}

Ao que se sabe, existe uma carência de informações acerca do controle reprodutivo em cutias, conforme a literatura científica corrente. $\mathrm{O}$ presente estudo demonstrou que o uso da prostaglandina isoladamente ou em associação com análogo de $\mathrm{GnRH}$ apresenta limitada eficiência na indução do estro em $D$. leporina, sendo particularmente efetivo naquelas fêmeas que estavam em fase luteal por ocasião da administração dos fármacos.

Em mamíferos, de forma geral, o uso de prostaglandina ou seus análogos deve ser empregado quando existe corpo lúteo ativo, sendo recomendada a administração de duas injeções de prostaglandina com o objetivo de promover a lise do corpo lúteo que não foi formado na primeira ocasião (Maia et al., 2014). Diante disso, no presente estudo, duas fêmeas $(2 / 5)$, as quais estavam inicialmente em fase luteal, mostraram sinais de estro aos três e seis dias após administração da última dose. As taxas de ocorrência de estro e a resposta tardia foram semelhantes às observadas por Pallares e Gonzalez-Bulnes (2009) em camundongos (Mus musculus) quando se utilizou prostaglandina em uma dose fixa de $0,5 \mu \mathrm{g}$ por animal, dose inferior à administrada no presente estudo $(5 \mu \mathrm{g})$. Vale ressaltar que aplicações de prostaglandinas em momentos aleatórios do ciclo estral podem coincidir com folículos pré-ovulatórios, reduzindo possivelmente o intervalo do início do estro à ovulação (Maffili et al., 2005). Dessa forma, não se descarta a possibilidade de esse evento ter ocorrido nas demais fêmeas, em razão de as coletas sanguíneas terem sido realizadas em intervalos de três dias. Porém, uma redução no intervalo do monitoramento seria dificultoso, haja vista a necessidade de anestesiar os animais.

Em camundongos (Mus musculus), o uso de cloprostenol $(0,5 \mu \mathrm{g})$, quando comparado a outros métodos de indução de estro, especificamente a progesterona $(9 \mu \mathrm{g})$ e a exposição ao macho, reduziu a taxa de fertilidade de $100 \%$ para $50 \%$ (Pallares e Gonzalez-Bulnes, 2009). Similarmente, em porquinho-da-índia (Cavia porcellus), injeções de análogos de prostaglandina (D-cloprostenol, D,L-cloprostenol e luprostiol) não modificaram o tempo de duração do ciclo estral, e todos os animais apresentaram resposta tardia e irregular, em média 16,4 \pm 0,4 dias após a última aplicação (Gregoire et al., 2012). Assim, os resultados mostram a necessidade de cautela no uso de prostaglandina em roedores, provando que esse fármaco pode não ser eficiente quando administrado isoladamente (Pallares e GonzalezBulnes, 2009). Entretanto, em estudo recente com ratos (Rattus norvegicus), Wei et al. (2015) testaram diferentes doses de cloprostenol $(10,15$ e $20 \mu \mathrm{g}$ ) administrados em dose dupla com intervalo de quatro dias, em grupos de fêmeas uniformes, todos durante a puberdade (30 dias de idade), e observaram que o melhor protocolo consistiu no uso de $15 \mu \mathrm{g}$, que resultou em uma taxa de 93,3\% de sincronização de estro. Ressalta-se que essa dose é maior que a utilizada no presente estudo com cutias $(5 \mu \mathrm{g})$. Assim, estudos futuros são sugeridos, no intuito de se identificar a dose mais apropriada em cutias, visto que o uso de drogas exógenas em roedores pode apresentar diferentes atividades na indução de estro, dependendo do estágio do ciclo estral (Zhang et al., 2007).

No tocante ao uso de prostaglandina em associação com análogo do GnRH, foram observados $60 \%$ (3/5) de eficiência para indução de estro em cutias da espécie $D$. leporina. Entretanto, não se pode descartar que um dos animais tenha apresentado um estro natural, haja vista que sua manifestação estral ocorreu tardiamente aos 10 dias após o término do tratamento. Em todo caso, associações de fármacos são rotineiramente usadas para indução e sincronização de estro em animais domésticos (Titi et al., 2010), e estudos recentes associando prostaglandinas com gonadotrofinas ou progestágenos têm demonstrado resultados promissores em roedores (Uslu et al., 2012). Em ratos (Rattus norvegicus), a combinação de cloprostenol e eCG tem permitido sincronização de estro em três dias (Wei et al., 2015), resultados similares ao do presente estudo, no qual $40 \%$ das fêmeas de $D$. leporina mostraram estro após quatro dias da última aplicação. Por outro lado, as maiores taxas de fertilidade e sincronização em roedores são descritas em porquinho-da-índia (Cavia porcellus) (Gregorie et al., 2012) e camundongo (Mus musculus) (Pallares e Gonzalez-Bulnes, 2009) tratados com associação de prostaglandina e análogos de progesterona, um protocolo que poderá ser aplicado e testado em cutias em um futuro próximo. 
Quando observadas as fêmeas que apresentaram estro, independentemente do tratamento utilizado, seus sinais externos de estro foram similares àqueles previamente reportados para fêmeas em estro natural (Campos et al., 2015). Essas observações concordam com o aumento de células superficiais $(100 \%)$ e a detecção de desenvolvimento de folículos ovarianos (40\%) por meio da ultrassonografia em fêmeas de $D$. leporina responsivas aos protocolos, semelhantemente ao descrito no estro natural para a espécie (Campos et al., 2015). A influência do estrógeno nas células superficiais tem sido descrita em outra espécie de cutias, a $D$. prymnolopha (Guimarães et al., 2011), na qual o pico de estrógeno foi, em média, 82,2 \pm $11,0 \mathrm{pg} / \mathrm{mL}$ (variando de 74,4 a $90,0 \mathrm{pg} / \mathrm{mL}$ ), um valor maior do que aquele descrito para $D$. leporina no presente estudo. Enfatiza-se, entretanto, que cada diferença poderia ser atribuída não somente às características da espécie, mas também aos diferentes métodos usados na dosagem hormonal (radioimunoensaio e quimioluminescência amplificada, respectivamente), o que impossibilitaria uma comparação direta entre os valores encontrados entre eles. Além disso, ressalta-se que os valores de estrógeno descritos durante o ciclo estral natural em D. prymnolopha apresentaram uma grande variação individual, verificando-se valores basais de $62,6 \mathrm{pg} / \mathrm{mL}$ e valores de pico de $2.031,0 \mathrm{pg} / \mathrm{mL}$ (Guimarães et al., 2011), cuja característica de variação poderia ser extrapolada para D. leporina.

Em D. prymnolopha, a ovulação espontânea ocorreu depois do pico de progesterona $(2,8 \pm$ $2,3 \mathrm{ng} / \mathrm{mL}$ ), possivelmente indicando que esse hormônio esteja associado com o processo de ovulação (Guimarães et al., 2011). No presente estudo, três de cinco fêmeas que manifestaram estro, se somados os resultados de ambos os tratamentos, mostraram um ligeiro aumento nos valores para progesterona $(5,7 \pm 1,1 \mathrm{ng} / \mathrm{mL})$ três dias após o dia do pico de estrógeno, uma vez que, antes desse dia, as fêmeas apresentaram valores de progesterona de $3,5 \pm 0,2 \mathrm{ng} / \mathrm{mL}$ e 2,4 $\pm 0,1 \mathrm{ng} / \mathrm{mL}$. O aumento da progesterona após o pico de estrógeno é também reportado em outros roedores histricomorfos, como porquinhos-daíndia (Croix e Franchmont 1975), e poderia estar associado com alta produção de progesterona durante o estro pelos folículos pré-ovulatórios (Guimarães et al., 2011). De fato, folículos observados por ultrassonografia coincidiram com as fêmeas que apresentaram altos valores para progesterona no presente estudo $(8,5$ a $3,7 \mathrm{ng} / \mathrm{mL}$ ).

A visualização dos folículos ovarianos por ultrassonografia em $D$. leporina foi possível em somente $40 \%(2 / 5)$ das fêmeas que mostraram influência de drogas exógenas. Contudo, não se pode descartar a existência de folículos em outras fêmeas que apresentaram estro. Em estudo prévio conduzido na mesma espécie, essa dificuldade no monitoramento de estruturas ovarianas por ultrassonografia durante o ciclo estral foi enfatizada (Campos et al., 2015). Tal dificuldade pode estar relacionada com a topografia dos ovários, uma vez que estão localizados na margem mesovárica, e sua face lateral é coberta pela mesossalpinge (bolsa ovárica) (Almeida et al., 2003). Além disso, a dimensão reduzida do ovário de cutias poderia ter contribuído para a dificuldade da visualização.

Pela perspectiva ecológica, a reprodução em mamíferos consiste em um processo complexo, que deve ocorrer de maneira harmoniosa entre o contexto dietético, físico (temperatura e fotoperíodo) e social (Busso et al., 2012). Em cutias, os efeitos desses fatores comportamentais da atividade gonadal não foram ainda individualmente estudados (Avigdor et al., 2004). Salienta-se que o grupo de cutias dos quais os animais utilizados neste experimento foram oriundos estava naturalmente exposto à latitude tropical, onde $\mathrm{o}$ fotoperíodo e a temperatura apresentam baixas variações ao longo do ano, o que deveria permitir longas estações reprodutivas, ao menos quando eles estivessem em vida livre (Bronson, 2009). Nas condições de cativeiro, esse grupo de animais estava submetido a um manejo nutricional aparentemente satisfatório. Apesar disso, anualmente, tem-se verificado uma significativa redução no desempenho reprodutivo desses animais durante a longa estação seca que acomete a região semiárida, possivelmente em virtude das condições de estresse decorrentes da elevação térmica nesse período. De fato, sabe-se que o estresse, seja ele gerado pelas condições de cativeiro, de contenção ou de ambiência (Kaiser et al., 2011), quando aplicado durante o desenvolvimento e a maturação folicular, diminui significativamente o potencial de 
desenvolvimento de oócitos em roedores. Diante desse fato, justificou-se a necessidade de formulação de protocolos para o controle do estro nas cutias mantidas em cativeiro, visando melhorar seu desempenho reprodutivo, em especial durante a estação seca.

\section{CONCLUSÃO}

Constatou-se que, de acordo com os protocolos utilizados, o uso da prostaglandina isolada ou em associação com análogo do GnRH para a indução do estro em cutias $D$. leporina apresenta eficiência limitada às fêmeas que estejam em fase luteal por ocasião do início do tratamento. Enfatiza-se que esses resultados se configuram um passo inicial para o controle do estro em cutias, sendo necessária a continuidade de estudos para seu aperfeiçoamento, haja vista o vislumbre de sua aplicabilidade visando à melhoria da gestão da espécie em cativeiro.

\section{REFERÊNCIAS}

AGCA, A.; YAKAN, A.; AGCA, Y. Estrus synchronization and ovarian hyper-stimulation treatments have negligible effects on cumulus oocyte complex gene expression whereas induction of ovulation causes major expression changes. Mol. Reprod. Dev., v.80, p.102-117, 2013.

ALMEIDA, M.M.; CARVALHO, M.A.M.; CAVALCANTE FILHO, M.F. et al. Estudo morfológico e morfométrico do ovário de cutias (Dasyprocta aguti Linnaeus, 1766). Braz. J. Vet. Anim. Sci., v.40, p.55-62, 2003.

AVIGDOR, M.; SULLIAVAN, S.D.; HEIDEMAN, P.D. Response to selection for photoperiod responsiveness on the density and location of mature GnRH-releasing neurons. Am. J. Physiol. Regul. Integr. Comp. Physiol., v.288, p.226-1236, 2004.

BARTOSKOVA, A.; ONDRACKOVA, P.; LEVA, L. et al. The effects of in vitro exposure to progesterone and estradiol-17 $\beta$ on the activity of canine neutrophils. Vet. Med., v.59, p.202209, 2014.

BRONSON, F.H. Climate change and seasonal reproduction in mammals. Philos. Trans. $R$. Soc. Lond. B Biol. Sci., v.27, p.3331-3340, 2009.
BUSSO, J.M.; PONZIO, M.F.; FIOL DE CUNEO, M. et al. Reproduction in chinchila (Chinchilla lanígera): current status of environmental control of gonadal activity and advances in reproductive techniques. Theriogenology, v.78, p.1-11, 2012.

CAMPOS, L.B.; PEIXOTO, G.C.X.; LIMA, G.L. et al. Monitoramento do ciclo estral de cutias (Dasyprocta leporina Lichtenstein, 1823) através de citologia esfoliativa vaginal e ultrassonografia. Pesqui. Vet. Bras., v.35, p.188192, 2015.

CARVALHO, M.A.M.; AZEVEDO, L.M.; MENEZES, D.J.A. et al. Anatomical-surgical arterial segments of the kidney in agouti (Dasyprocta prymnolopha). Pesqui. Vet. Bras., v.28, p.249-52, 2008.

CROIX, D.; FRANCHIMONT, P. Changes in the serum levels of gonadotrophins progesterona and estradiol during the estrous cycle of the guinea pig. Neuroendocrinology, v.19, p.1-11, 1975.

FORTES, E.A.M.; CARVALHO, M.A.M.; ALMEIDA, M.M. et al. Aspectos morfológicos da tuba uterina de cutias (Dasyproct aguti Mammalia: Rodentia). Braz. J. Vet. Anim. Sci., v.42, p.135-142, 2005.

GREGOIRE, A.; ALLARD, A.; HUAMAN, E. et al. Control of the estrous cycle in guinea-pig (Cavia porcellus). Theriogenology, v.78, p.842847, 2012.

GUIMARÃES, D.A.; RAMOS, R.L.; OHASHI, O.M. et al. Plasma concentration of progesterone and 17-estradiol of black-rumped agouti (Dasyprocta prymnolopha) during the estrous cycle. Rev. Biol. Trop., v.59, p.29-35, 2011.

KAISER, S.K.; MARGARDO, T.C.C.; FISCHE, M.L. Avaliação do comportamento de cutias Dasyprocta azarae e Dasyprocta leporina (Rodentia: Dasyproctidae) em cativeiro e semicativeiro em parques urbanos de Curitiba, Paraná, Brasil. Rev. Etol., v.10, p.68-82, 2011.

LOPES, J.B.; CAVALCANTE, R.R.; ALMEIDA, M.M. et al. Desempenho de cutias (Dasyprocta prymnolopha) criadas em cativeiro do nascimento até o desmame em Teresina, Piauí. Rev. Bras. Zootec., v.33, p.2318-2322, 2004. 
MAFFILI, V.V.; TORRES, C.A.A.; FONSECA, J.F. et al. Estrus synchonization of Saanen goats with intravaginal sponge and CIDR-G ${ }^{\circledR}$. Arq. Bras. Med. Vet. Zootec., v.57, p.591-598, 2005.

MAIA, K.M.; PEIXOTO, G.C.X.; CAMPOS, L.B. et al. Estrous Synchronization in captive collared peccaries (Pecari tajacu) using a prostaglandin F2 $\alpha$ analog. Zool. Soc., v.31, p.836-839, 2014.

PALLARES, P.; GONZALEZ-BULNES, A. A new method for induction and synchronization of oestrus and fertile ovulations in mice by using exogenous hormones. Lab. Anim., v.43, p.295299, 2009.

PFEIFER, L.F.M.; LEONARDI, C.E.P.; CASTRO, N.A. et al. The use of PGF2a as ovulatory stimulus for timed artificial insemination in cattle. Theriogenology, v.81, p.689-695, 2014.

RED list of threatened species. Version 2015-4. [Cambridge]: IUCN, 2015. Available in: $<$ www.iucnredlist.org $>$. Accessed in: 15 Feb. 2016.

RENSIS, R.; SCARAMUZZI, R. Heat stress and seasonal effects on reproduction in rodents. Theriogenology, v.60, p.1139-1151, 2003.

RODRIGUES, R.F.; MIGLINO, M.A.; FERRAZ, R.H.S. et al. Placentação em cutias (Dasyprocta aguti, Carleton M.D.). Aspectos morfológicos. Braz. J. Vet. Anim. Sci., v.40, p.133-137, 2003.
SILVA, A.R.; SOUZA, A.L.P.; SANTOS, E.A.A. et al. Formação de bancos de germoplasma e sua contribuição para a conservação de espécies silvestres no Brasil. Cienc. Anim., v.22, p.219-234, 2012.

TITI, H.H.; KRIDLI, R.T.; ALNIMER, M.A. Estrus synchronization in sheep and goats using combinations of $\mathrm{GnRH}$, progestagen and prostaglandin F2alpha. Reprod. Domest. Anim., v.45, p.594-599, 2010.

USLU, B.A.; TASAL, I.; GULYUZ, F. et al. Effects of oestrus synchronisation using melatonin and norgestomet implants followed by eCG injection upon reproductive traits of fattailed Morkaraman ewes during suckling, anoestrus season. Small Ruminant Res., v.108, p.102-106, 2012.

WANDERLEY, L.S.; MACHADO, L.H.; FAUSTINO, L.R. et al. Ultrastructural features of agouti (Dasyprocta aguti) preantral follicles cryopreserved using dimethyl sulfoxide, ethylene glycol and propanediol. Theriogenology, v.77, p.260-267, 2012.

WEIR, S.; GONG, Z.; NA, L. et al. Cloprostenol and $\mathrm{eCG}$ influence oestrus synchronisation and uterine development in mice. Vet. Med., v.60, p.31-38, 2015.

ZHANG, Y.; LAI, W.P.; LEUNG, P.C. et al. Short to mid-term effects of ovariectomy on bone turnover, bone mass and bone strength in rats. Biol. Pharm. Bull., v.30, p.898-903, 2007. 